\title{
Gênero, origem social e (auto)biografia: processos de formação e relação com a escolaridade
}

Elisangela Melnik Trombetta* Fabio Machado Pinto**

\begin{abstract}
Resumo:
O presente trabalho resulta de uma pesquisa de mestrado desenvolvida em um colégio federal, na qual buscamos compreender os processos de formação de escolares que frequentam a educação básica: irmão e irmã oriundos de classes populares que apresentam diferentes relações com a escolaridade. Neste artigo, demarcaremos o estudo das relações das figuras femininas que participaram da pesquisa. A importância da condição socioeconômica e cultural da família é analisada face às intersecções entre gênero e rendimento escolar, sobretudo, nas atividades realizadas pela estudante sob mediação de adultos e pares, com atenção especial na mediação materna. Destacamos como a importância, o esforço e as estratégias que elas canalizam no estabelecimento de uma relação bem-sucedida com a escola e com os saberes, com destaque para as aprendizagens de autonomia e responsabilidade, que desdobram de uma disciplina e rotina cultivadas em casa entre elas.
\end{abstract}

\section{Palavras-chave:}

Sentido. Gênero. Relação com o saber. Autobiografia.

\begin{abstract}
${ }^{1}$ :
The present work results from a master's research developed at a federal school, in which we seek to understand the formation processes and the relationship with the scholarity of two young people who attend basic education. The study was carried out with two siblings from popular classes who have different relations with schooling. In this paper, we will outline the study of the relationships of the female figures who participated in the research. The importance of the socioeconomic and cultural condition of the family is analyzed in view of the intersections between gender and school performance, especially by the activities carried out by the student under the mediation of adults and peers, with special attention in maternal mediation. As a result, we highlight the importance, the effort and the strategies that they channel in establishing a successful relationship with the school
\end{abstract}

\footnotetext{
* Mestre em Educação pela Universidade Federal de Santa Catarina, professora dos anos iniciais no Colégio de Aplicação/UFSC, pesquisadora do Grupo de Estudos Biográficos Sartreano (GEBIOS). E-mail: elisangela.trombetta@ufsc.br. ORCID iD: https://orcid.org/0000-0001-9004-4901.

** Doutor em Educação pela Université Paris 8 - Saint Denis, professor na Universidade Federal de Santa Catarina (UFSC), coordenador do Grupo de Estudos Biográficos Sartreano (GEBIOS).

E-mail: fabiobage@yahoo.com. ORCID iD: https://orcid.org/0000-0002-9480-4493.

1. Agradecimento à Gabriela de Moraes Damé pela revisão do resumo em inglês e a Justina Sponchiado pelas contribuições na leitura e discussão do artigo, ambas da Equipe GEBIOS.
} 
and with the knowledge, with emphasis on the autonomy and responsibility learning, that unfold from a discipline and a domestic routine, cultivated among them.

\section{Keywords:}

Sense. Gender. Relationship with knowledge. Autobiography.

\section{Introdução}

O fracasso e o sucesso escolar são fenômenos que mobilizam pesquisadores e pesquisadoras no Brasil e no exterior, há décadas. De acordo com Patto (1997), já nos anos de 1920, os registros de reprovação e evasão na escola primária, no Brasil, preocupavam as autoridades. Desde então, houve avanços no que se refere à ampliação e ao acesso ao ensino público, principalmente nos últimos anos, em que o ensino fundamental se massificou no Brasil. Porém, a educação pública ainda não consegue democratizar os saberes escolares, de forma que as crianças do meio popular também tenham acesso aos conhecimentos, historicamente, acumulados pela humanidade e que lhes possibilitem avançar em seus estudos superiores. As pesquisas mostram que existe uma correlação entre a origem social das crianças e suas trajetórias escolares ${ }^{2}$. Observam-se, contudo, trajetórias de sucesso no meio popular que evidenciam a capacidade de superação de crianças e suas famílias, ainda que pesem sobre elas o enorme fardo de uma estrutura social e econômica desigual e injusta. O que explicaria tamanha complexidade? Essa questão tem provocado uma nova demanda investigativa, que se convencionou chamar de sociologia crítica da educação: "Por que será que certos alunos fracassam na escola? Por que será que esse fracasso é mais frequente entre famílias de categorias sociais populares do que em outras famílias?" (CHARLOT, 2000, p. 9).

No enquadramento das relações de famílias populares e a escola, as pesquisas desenvolvidas entre os anos de 1950 e 1970, por Pierre Bourdieu e sua equipe, demonstraram que o pertencimento social decidia as trajetórias escolares. As desigualdades de acesso e permanência na escola se acumulavam ao longo de sua escolarização. Essas variáveis permanecem nos dias atuais na realidade brasileira, confirmando a escola pública como um lugar de reprodução das desigualdades sociais, por meio de fracassos escolares para um grande contingente. Porém, nas últimas décadas ocorreu um lento processo de mobilidade social nas camadas sociais mais baixas. Esse respiro fez florescer experiências escolares que levaram alguns desses jovens aos bancos universitários, rumo às mais diversas profissões. São situações que envolvem trajetórias escolares de sucesso em famílias populares e que têm sido objeto de nossos estudos. Este artigo apresenta um duplo processo de sucesso e fracasso escolar, averiguado em estudo que resulta de pesquisa de mestrado ${ }^{3}$, tematizando o sentido da experiência escolar a partir da "noção de relação com o saber", desenvolvida pela Équipe Escol (CHARLOT; BAUTIER; ROCHEX, 1992); e do "método biográfico progressivo-regressivo" sartreano. Buscamos, então, compreender como os escolares fazem seus os projetos construídos no seio de uma família conduzida pelas mulheres mãe e avó, desenhando trajetórias diferentes e cujas discussões indicaram uma relação forte entre gênero e trajetória escolar.

\footnotetext{
2. Nos referimos à Teoria da Reprodução resultado dos estudos verificados em: BOURDIEU, Pierre; PASSERON, Jean-Claude. A reprodução: elementos para uma teoria do sistema de ensino. Rio de Janeiro: Francisco Alves, 1992.

3. Nos referimos à dissertação de Mestrado em Educação (PPGE/UFSC) de Elisangela Melnik Trombetta, intitulada $O$ sentido da experiência escolar no meio popular: irmãos em casa e na escola, defendida em agosto de 2019, orientada pelo Prof. Dr. Fábio Machado Pinto.
} 


\section{A noção de relação com saber e os estudos biográficos}

As trajetórias de sucesso em famílias provenientes de classes populares vêm sendo estudadas desde os anos de 1990, como por exemplo aqueles da Équipe Escol (CHARLOT; BAUTIER; ROCHEX, 1992; CHARLOT, 1996, 2000) ou de Lahire (1997) na França e, no Brasil, os de Silva (1999), Piotto (2008) e Vianna (2010). Estas pesquisas mostram a importância do esforço e do trabalho familiar na permanência e longevidade de seus filhos na escola. Vianna (2010) reitera que é possível ocorrer êxito nas camadas populares, mesmo na ausência da maioria das práticas escolares, como as descritas das classes médias.

Essas referências guiaram nosso estudo sobre a mediação de Marina $^{4}$ (mãe) para com os filhos, especificamente sua filha Karine, a menina mais nova e que nos permite refletir sobre as relações entre gênero e uma trajetória escolar de sucesso. A mãe, no momento da pesquisa, trabalhava em dois empregos, em um regime intermitente e outro informal e, por este motivo, residia parte do tempo em outra casa próxima ao trabalho. A avó, pensionista, continuava na ativa como funcionária em empresa terceirizada para complementar a renda familiar, residindo com as crianças. O pai, separado, encontrava os filhos esporadicamente. Karine tinha doze anos, cursava o sétimo ano, se autodeclarava de cor parda, nasceu no Rio Grande do Sul e morava em residência própria com sua mãe, sua avó materna e seu irmão. É a filha mais nova dessa família chefiada pela mãe em cooperação com a avó. Sua trajetória escolar é permeada de boas notas, amizades, elogios; mantém o ritmo tranquilo, sem convocações a recuperações de estudos ou reprovações. Tiago, o mais velho, se encontrava no sexto ano escolar e teve seu percurso marcado por aulas de recuperação e em duas séries ocorreram reprovações. Os irmãos seguiam, diariamente, um caminho de vinte quilômetros de sua residência até o colégio federal onde estudavam. Desde cedo, os irmãos desenvolveram com autonomia distintas tarefas domésticas que lhes ajudavam a lidar com situações que enfrentavam no seu dia a dia. Tiago e Karine fazem parte de um mesmo tecido sociológico, frequentam a mesma igreja e colégio, mas cada qual estabelece uma relação singular com as instituições das quais participam - família, escola, igreja - e com os seus saberes e aprendizagens.

As teorias de Charlot (2000) e Sartre (2002) nos ajudam a compreender a formação dos sujeitos como seres inacabados, em permanente construção por meio das relações que estabelecem nesses ambientes, das situações vividas entre eles e com outras pessoas e grupos, em meio a determinada materialidade que demarca seu campo de possíveis. Avó, pais, amigos, professores, entre outros, assim como os saberes disponíveis e disponibilizados nessas relações, são mediações importantes para que busquem uma identidade e desenvolvam suas personalidades. A relação com as instituições, esses ambientes de formação humana, é uma construção que depende, tanto das exigências e condições colocadas pelos adultos e instituições, quanto pelas escolhas que cada criança faz em cada ato, em cada ação, ainda que nem sempre sejam refletidas ou independentes daquilo que a cultura e seu tecido sociológico lhes exigem.

[...] o mundo, eu e o outro não são meras entidades. O mundo é aquele em que cada criança vive um mundo desigual, estruturado por relações sociais. Eu, o sujeito, é um aluno que ocupa uma posição, social e escolar, que tem uma história, marcada por encontros, eventos, rupturas, esperanças, a aspiração a ter uma boa profissão, a tornar-se alguém, etc. O outro são os pais que atribuem missões ao filho, professores que explicam de maneira mais ou menos correta, que estimulam ou, às vezes, proferem insuportáveis palavras de fatalidade. Não há relação com o saber se não a de um sujeito. Não há sujeito senão em um mundo e em uma relação com o outro. (CHARLOT, 2000, p. 73).

Para Sartre (2002), o "homem"5 vai se constituindo como um projeto, responsável por suas escolhas e movimentos, o que implica em considerar que nem todos os movimentos e escolhas são refletidos e obedecem a mesma lógica. Algo que aproxima o pensamento sartreano dos estudos de Charlot é a evidência

4. Todos os nomes atribuídos aos sujeitos da pesquisa são fictícios.

5. Neste artigo optamos por manter os termos utilizados por Sartre, mas destacamos a importância do uso de expressões que considerem o homem e a mulher igualmente. 
de que os escolares estão sempre fazendo algo daquilo que fizeram deles; estão se produzindo dentro de uma história maior que também é produzida por eles como um "projeto". Os escolares encontram-se em um momento de formação, quando seu projeto vem sendo mediado pelos adultos e a sociedade, pelos saberes e recursos disponíveis para enfrentar seus desafios e responder as exigências do dia a dia. Ao se apropriar do mundo em que se encontra, a criança estabelece relações de aprendizagem, o que lhes permite formar uma identidade e desenvolver sua personalidade, como algo que aparece na relação com aquilo que elas mesmas fazem, do que fizeram delas. Um "Eu" que estuda, que joga, que pega o ônibus, que lava a louça, que obedece às ordens da mãe, que reza, que gosta da escola, ou que diz para si mesmo: "eu não consigo aprender!". Na medida que esse "Eu" aparece no horizonte do seu pensamento como sendo ele mesmo, surge a possibilidade do cogito. Para Sartre (1994), a personalidade é transcendente, assim como sua condição de possibilidade, ou seja, as consciências que permitem o seu surgimento.

Para a maior parte dos filósofos o Ego é um "habitante" da consciência. Alguns afirmam sua presença formal no interior dos "Erlebnisse" como um princípio de unificação vazio. Outros - psicólogos na sua maior parte - pensam descobrir sua presença material, como centro de desejos e de atos, a cada momento de nossa vida psíquica. Pretendemos mostrar aqui que o Ego não está nem formalmente nem materialmente na consciência: ele está lá fora, no mundo, é um ser do mundo, como o Ego do outro. (SARTRE, 2010, p. 183).

Charlot (2000) ao promover a reflexão crítica sobre a posição social do estudante e sua família, se demarca frente à Teoria da Reprodução e se aproxima do pensamento de Sartre, que considera o movimento concreto das pessoas e grupos (no caso dos escolares e suas famílias). Para Sartre e Charlot, a família e seus membros constroem suas relações com os saberes e com o mundo, dando sentido as suas experiências, à escolaridade, às aprendizagens e a si mesmos nas relações que estabelecem. Por isso, faz sentido perguntar como eles se mobilizam para estudar e aprender os saberes e como ocorrem, objetiva e subjetivamente, esses processos de aprendizagem? O concreto nessa concepção teórica é a história, resultado da história humana desde as práxis individuais, ou seja, as relações humanas de forma concreta e como elas ocorrem nas situações. Conforme entendimento de Schneider (2008, p. 292), “[é] preciso destacar a especificidade da existência humana, ao tomar o homem concreto na sua realidade objetiva, material, sociológica".

Essa concepção considera a temporalidade humana como um passado formado pelas gerações anteriores e tudo que puderam produzir para que hoje possamos nos "escolher"; um presente em que as ações implicam a realidade e indicam nosso destino ou para onde nos dirigimos; nosso futuro, para onde nos dirigimos com cada um de nossos atos e quanto mais forte ele se coloca na forma do desejo, mais sentido dá as nossas ações no presente. Os fenômenos são um conjunto de ocorrências tecidas umas as outras. Ao modificar uma de suas variáveis, ele se modifica, o que nos remete para o estudo das relações, imbricações, distanciamentos, objetivações em seu conjunto, em uma perspectiva histórica e dialética. Esse método (auto)biográfico compreende o ser humano inscrito em sua época, evidenciando como o estudo de situações de sucesso e fracasso escolar exige ferramentas conceituais e metodológicas sofisticadas. Pedro Bertolino (2008) ${ }^{7}$ explica sobre a mediação fundamental nos estudos sartreanos que realizamos, que é possível compreender o sujeito, tendo como ponto de partida a concretude da realidade humana, que precisa ser alcançada nas dimensões antropológica ou cultural no sentido amplo; no tecido sociológico de que fazem parte a família e os grupos; e na sua dimensão psicofísica. Isso vem ao encontro do que diz Charlot (2000, p. 53), sobre o humano e o tríplice processo de hominização, singularização e socialização. A educação seria o meio pelo

\footnotetext{
6. Para conhecer o modelo 17 - "Evolução da Personalidade pelo Cogito Pessoal”, explicativo do projeto e desejo de ser em Sartre, consultar a página do Núcleo de Estudos e Atividades EM Existencialismo (NUCA): https://nuca.org.br/modelos-cientificos/.

7. Para conhecer o modelo 19 - "Geração do Dinamismo Socio-antropológico", explicativo da "constituição dinâmica das personalidades" tridimensional (sujeito, sociológico, antropológico), constituído a partir do estudo sartreano, consultar a página do NUCA: https://nuca.org.br/modelos-cientificos/.
} 
qual a criança se constrói humana, ao mesmo tempo em que é social, também se faz singular. Charlot (2000) destaca que a mediação do outro é essencial, mas enfatiza que não haverá educação sem consentimento.

Ninguém poderá educar-me se eu não consentir, de alguma maneira, se eu não colaborar; uma educação é impossível, se o sujeito a ser educado não investe pessoalmente no processo que o educa. Inversamente, porém, eu só posso educar-me numa troca com os outros e com o mundo; a educação é impossível, se a criança não encontra no mundo o que lhe permite construir-se. Toda educação supõe o desejo, como força propulsionadora que alimenta o processo. Mas só há força de propulsão porque há força de atração: o desejo de; a criança só pode construir-se porque o outro e o mundo são humanos e, portanto, desejáveis. (CHARLOT, 2000, p. 54).

Charlot e sua equipe se dedicam a estudar as formas como cada família e cada criança mobilizam seus recursos para construir uma boa relação com sua escolaridade e saberes. Como estudam e se apropriam dos saberes escolares? Que tipo de atividade intelectual realizam? Esse encontro de visões micro e macrossociológica nos levou ao método progressivo-regressivo, que estuda o fenômeno como um universal/ singular, portanto, é quali-quanti ${ }^{8}$ : seu ponto de partida é uma história singular, mas não se reduz a um estudo de caso, pois precisa situar o singular em uma sociedade e época, em grupos, para retornar ao singular. Este duplo movimento busca tomar o fenômeno em sua temporalidade (passado, presente, futuro) e em sua humanidade (antropológico, sociológico, psicofísico), o que caracteriza sua racionalidade científica e dialética.

\section{Os instrumentos de pesquisa (auto)biográfica sartreana}

Uma vez demarcado o nosso objeto, iniciamos uma pesquisa exploratória em que verificamos e analisamos os documentos escolares relacionados aos sujeitos com perfil para a pesquisa: escolares na transição dos anos iniciais para os finais, oriundos de classes populares ${ }^{9}$, que apresentassem, em sua trajetória, situações de fracasso escolar. Segundo as análises de Vianna (2010), o êxito nas primeiras séries do ensino fundamental é um fator central para o início da construção de uma trajetória escolar prolongada.

A definição dos sujeitos da pesquisa foi realizada por meio de análise preliminar de atas de conselho de classe, registro na ficha individual dos alunos, espelho de frequência, boletins escolares, convocação em Recuperação de Estudos $(\mathrm{RE})^{10}$ nas três turmas de quinto ano em 2017, com especial atenção na relação de estudantes que frequentaram a recuperação, ao longo do referido ano, e reprovaram. Verificamos a situação dos irmãos que nos chamou atenção: um aluno mais velho vivendo uma situação de fracasso escolar e sua irmã mais nova, realizando uma trajetória bem-sucedida. Decidimos por continuar com este desafio e tentar compreender como a situação ocorria por dentro do processo. Cabe destacar, que ao longo da pesquisa, levamos em consideração o que Schneider (2008) ressalta sobre o método biográfico realizadas por dentro.

O fato de cada sujeito ser um ser social, coletivo, universal, mas ao mesmo tempo, ser um ser único, singular, ou seja, em cada homem encontrarem-se, simultaneamente, as marcas da cultura, da classe social, do momento histórico em que vivem, bem como as da apropriação subjetiva que ele faz de todos esses determinantes, tornando-se alguém específico. (SCHNEIDER, 2008, p. 297-298).

\footnotetext{
8. Concordamos com Minayo e Sanches (1993) sobre a perspectiva quantitativa-qualitativa, trabalhadas em complementaridade, conforme as particularidades do objeto de pesquisa.

9. Nesta pesquisa, utilizamos os termos "classes populares" e "meios populares", quando se refere aos grupos menos favorecidos em relação aos aspectos socioeconômicos e culturais e que não detém o capital linguístico socialmente reconhecido e legitimado. 10. As recuperações de estudos, no Colégio de Aplicação, acontecem semanalmente durante o ano todo, por série, em horários extraclasse. Uma hora-aula antes do início das aulas ou, posteriormente, ao término do horário das aulas regulares. E, no final do ano, ainda há as recuperações finais antes da decisão de reprovação ou aprovação.
} 
Na fase exploratória, em 2018 - quando ela havia avançado em seus estudos e ele encontrava-se um ano atrás na escolaridade - buscamos investigar a realidade escolar vivida por ambos. Observamos os mesmos nos espaços escolares e aplicamos um questionário ${ }^{11}$ a todos da sua turma do quinto e sexto anos do colégio, séries frequentadas pelos sujeitos da pesquisa. Durante duas semanas observamos as situações de aprendizagem no espaço escolar e levantamos hipóteses sobre suas relações com a escola e com os saberes. Essa etapa orientou a elaboração de um questionário que pudesse dar uma visão panorâmica do perfil estudantil de referência nestas séries. Essas observações e informações proporcionaram uma visão horizontal do clima escolar e de suas relações com seus pares, professores, servindo de base para a elaboração do roteiro de entrevista biográfica semiestruturada.

As entrevistas (auto)biográficas foram realizadas, primeiramente, com a mãe e, posteriormente, com os irmãos, em separado. Elaboramos dois roteiros, um para a mãe e outro para Tiago e Karine. Depois da identificação pessoal e familiar, o roteiro estabeleceu uma conversa sobre a escolaridade vivida naquele momento por eles e acompanhada pela mãe, descrevendo e comentando os episódios e situações que pudessem evidenciar como ocorriam os estudos, os deslocamentos, os deveres, os recreios, as brincadeiras e jogos, a relação com professores e colegas, bem como com os espaços e tempos escolares, enfim com os saberes e aprendizagens que ocorrem nesse contexto. Em continuidade, abordamos o vivido fora da escola, em casa e em outros espaços, tomando o cuidado de ir para o concreto das relações vivenciadas, desde os afazeres domésticos, os momentos de convívio com avó, mãe, pai, amigos, educadores da Igreja, mas também, com os aparelhos como celulares, televisão, entre outros. O roteiro preestabelecido partia do presente e das situações concretas vividas e buscava historicizar suas relações, desde o passado com a mãe descrevendo e comentando sua própria escolaridade e o sentido dessas experiências, e as crianças, elaborando suas vidas desde as mudanças de cidade, bairro e escola, as relações construídas nesse movimento, que pudessem esclarecer os processos de construção do vivido no presente. Uma terceira etapa da entrevista focou nos aspectos vivenciados e projetados por eles, como o futuro e o que pretendem realizar, em termos de saberes, habilidades, relações e, até mesmo, de profissões a serem alcançadas. Buscamos evidenciar, dessa forma, o projeto e desejo de ser, se formando por meio da observação das suas ações e da elaboração que fazem das mesmas.

O processo de entrevista (auto)biográfica reuniu os elementos fundamentais para construir uma inteligibilidade sobre o sucesso e o fracasso escolar dos estudantes, ao mesmo tempo em que se constituiu em um processo de (auto)formação, pois auxiliaram os entrevistados a rememorar suas próprias histórias, suas relações e escolhas, o caminho percorrido até o momento e perspectivas de futuro. O sentido da experiência escolar só pode ter lugar no encontro - nem sempre coerente e harmonioso - entre as duas dimensões, da objetividade e da subjetividade. Isso exigiu um retorno a literatura especializada para viabilizar uma melhor compreensão do objeto estudado.

Neste artigo nos preocupamos em evidenciar a relação entre Marina e sua filha, como verificamos na mediação fundamental em sua escolaridade, considerando o evocado por Sartre com base em Marx, que "os homens fazem a história, eles próprios, a sua história, mas num meio dado que as condiciona" (SARTRE, 2002, p. 74). E acrescenta que as circunstâncias e a educação que os produzem são modificadas precisamente por estes mesmos homens, tanto que o educador deve ser, ele próprio, educado.

Na continuidade, teceremos algumas reflexões sobre a mediação entre mãe e filha, na construção dos processos escolares bem-sucedidos, em que os estudos biográficos nos permitem analisar e compreender.

\footnotetext{
11. Vale lembrar que os estudantes foram convidados a responder ao questionário, não havendo obrigatoriedade. Todos os presentes no dia de aplicação participaram da pesquisa, totalizando 88\% (132) de participação dos escolares de todas as turmas do 5ㅇ e 60 ano do CAp. O preenchimento do questionário ocorreu entre meados de novembro e início de dezembro de 2018. Cabe destacar que esses dados, respostas aos questionários, são fundamentais para compreendermos o universo escolar no qual estão inseridos os participantes deste trabalho: Quem são os estudantes dessas séries? Os irmãos possuem perfil muito distante dos demais? Há semelhanças e diferenças significativas nas comparações dos dados coletivos e dos irmãos? Qual sua representatividade no conjunto dos escolares? Esses dados nos ajudam a compreender como esses sujeitos estão se formando nessa relação entre o singular e o universal?
} 


\title{
Resultados e discussões
}

\section{Mediação materna e seus dilemas: subsistência ou acompanhamento escolar}

É comum nas classes populares que as famílias mantenham boas expectativas quanto à escola, principalmente, as relacionadas à mobilidade social. O valor atribuído aos estudos e a escola dos filhos de classes populares pode ser comparado a um "tesouro que ninguém rouba" e que lhe proporciona oportunidades antes não alcançáveis. A fala de Marina (mãe dos escolares estudados) confirma a perspectiva dessa família em relação à educação de seus filhos, desde suas memórias de escolaridade e daquilo que seus pais, na época, costumavam sempre lembrar:

\begin{abstract}
Marina: [...] A única coisa que ele [pai de Marina e avô dos estudantes] pedia era pra estudar. Que a única coisa que ninguém podia tirar de nós era o estudo. A única coisa que ele dizia: "Ah... Que que tu vai fazer da vida, a única coisa que ninguém pode tirar de ti é o teu estudo. Casa, roupa, comida podem te tirar, mas a sabedoria, nunca”. A única coisa que eu lembro assim que ele falava que era pra estudar que ele não teve oportunidade. [...] O que tu sabe, o teu conhecimento, é a única coisa que ninguém pode roubar porque tá dentro de ti, dentro da tua cabeça o teu conhecimento e pode te abrir portas. E... Que a gente pode conquistar um bom emprego, que a gente pode ter um futuro melhor do que meu pai e minha mãe tiveram né. Essa é a questão. E é isso que eu falo pros meus filhos.
\end{abstract}

Para a sua família, a educação escolar era uma prioridade e uma via necessária para uma possível mobilidade social ou um futuro melhor. Marina é natural de uma cidade do interior do Rio Grande do Sul e cresceu em uma família nuclear tradicional, no qual pai e mãe cooperavam para o bem-estar familiar. O pai, funcionário público federal, embora muito inteligente e dedicado, desempenhava funções além das listadas em seu posto funcional, mas a falta da educação formal delimitou seu progresso na referida instituição - fato sempre rememorado nas conversas de família para motivar os filhos aos estudos. Como seu pai trabalhava fora, seguindo uma tradição, as regras de casa, o acompanhamento escolar, a supervisão e cobranças das tarefas escolares ficavam a cargo da mãe.

O processo de escolarização de Marina foi permeado de dificuldades, em uma luta constante para conquistar seu espaço. Ela gostava da escola e se esforçava em realizar todas as atividades escolares exigidas, além das atividades extras que sua mãe lhe pedia. Mas a relação com a escolaridade foi se deteriorando por conta de algumas situações vivenciadas com alguns professores, da forma como a mãe conduzia os estudos em casa, pela comparação com as trajetórias dos irmãos e, por fim, pelas próprias escolhas de Marina. Situação que acabou fazendo-a se encaminhar desde cedo, aos 12 anos, para o mercado de trabalho em busca de complementação da renda e de uma identidade nesse ambiente familiar.

Marina: [...] Com doze anos minha mãe pintava panos de pratos e meu pai vendia no trabalho dele. Daí eu tive a ideia de ajudar a vender. Eu lembro que eu batia na porta dos vizinhos pra vender mel, vender pano de prato pra ajudar em casa. Meus irmãos nunca fizeram isso. [...] Eles sempre estudando. E aí... Com dezoito anos que eu me formei. Aí comecei a trabalhar, fiz um estágio e depois comecei a trabalhar. Aí depois não estudei mais. Fiz até vestibular, pré-vestibular também.

Marina tinha a percepção de que cooperar para o sustento da família, a fazia se sentir melhor, criando uma identidade e trajetória particular nesse seio. Contudo, isso parece não ter ficado bem resolvido e avalia que o trabalho dificultou o retorno aos estudos e só com muito esforço conseguiu concluir o ensino médio. Há muito mais elementos na entrevista (auto)biográfica que evidenciam essa construção, de uma relação complicada com a escolaridade e que também conspiraram para seu afastamento da educação formal, tal qual seu pai. $O$ valor da escolaridade se manteve, isso que ela não pode usufruir em plenitude, lembrado como uma falta que poderia ter mudado seu presente e futuro. 
Sua (auto)biografia incorpora as mudanças culturais e sociais ao longo dos tempos, como por exemplo, a organização familiar na casa dos pais (tradicional) e a família que chefia atualmente, monoparental, dividida com sua mãe. Esta configuração sociológica é que serve de mediação para a formação de seus filhos e constituição de suas personalidades, tanto quanto o clima antropológico, no qual essa família se insere. É fato que a instituição familiar precisou se reinventar através do tempo, acompanhando as mudanças econômicas e socioculturais de cada contexto em que se encontram inseridas, possibilitando novos formatos que convivem com aspectos do tradicional vivido pelas gerações passadas. $\mathrm{O}$ novo vem sempre permeado do velho, mas ainda assim, um novo, criando as condições para um campo de possíveis, diferente daquele em que a geração de sua mãe e a sua própria, foram educadas.

Essa é a experiência vivida por ela hoje, de transformação relacionada as novas configurações familiares, como filha e irmã e, agora, como filha e mãe. Segundo Cavenaghi e Alves (2018), analisando os dados do IBGE da última década, o número de famílias chefiadas por mulheres mais que dobrou nos últimos quinze anos, chegando a 28,9 milhões em 2015. No meio popular, “a mobilização familiar é voltada, em primeiro lugar, para a sobrevivência, e é graças ao rendimento coletivo do grupo, decorrente do trabalho de seus integrantes, que este tenta assegurar suas necessidades básicas" (ZAGO; CARVALHO; VILELA, 2010, p. 26). O exemplo da avó e mãe, mulheres da família, parecem surtir efeito na formação dos netos e filhos, que abraçam o trabalho coletivo ainda que com certa divisão de gênero nas tarefas a efetuar, mas cumprem um ritual de afazeres e aprendizagens que lhes permitem aprender a sobreviver coletivamente, fortalecendo os vínculos familiares.

Marina exprime por meio de suas narrativas, suas responsabilidades e esforços, mas sobressai o impasse que a aflige. Evoca um sentimento mesclado de cumprimento de dever e de culpa. Ela se empenha na busca do sustento, mas por isso não dispõe de tempo para o acompanhamento de seus filhos. Sua ausência em relação as questões escolares dos estudantes aparece ao longo das entrevistas, assim como seu desejo de estar mais presente. Foi por meio dos relatos que constatamos suas estratégias e esforços dirigidos ao investimento escolar dos filhos entre tantas dificuldades. Marina relembra que quando casada, priorizou o acompanhamento dos filhos, em especial do menino que apresentava dificuldades, desligando-se do trabalho e reduzindo o orçamento familiar. Também lembra da alegria por ter conseguido matricular os filhos no colégio federal, que ocorre por meio de sorteio público de vagas: "Aí, eu agradeci muito, eu chorei muito, eu disse: Meu Deus, é a melhor coisa que eu consegui pra mim. Vai ser difícil? Vai. Vai ser puxado? Vai. Mas eu vou correr atrás!”.

Nossos dados demonstram ${ }^{12}$ a importância da figura materna no investimento escolar dos filhos. Os estudantes que apresentam trajetória escolar permeada por convocações em recuperação de estudos e reprovações, contabilizam sua maior proporção na realização dos deveres “sem acompanhamento" - a saber, $56 \%$ dos discentes realizam os deveres sozinhos. Universo este desenhado por famílias monoparentais, cuja carga de subsistência do grupo familiar recai sobre a figura materna. O esforço da mãe nem sempre é o suficiente, fato é que o seu filho mais velho encontra dificuldades nos estudos, o que acabou sendo contornado pelo esforço da filha em um movimento de autonomia e organização das tarefas de casa, deveres, estudos e que vem sendo bem-sucedida. Isso evidencia a importância de observar e estudar no detalhe, as atividades das crianças, como se configuram a partir do que os adultos lhes proporcionam em termos de mediação para a aprendizagem escolar.

No enquadramento de suas possibilidades, Marina segue a diligência em acompanhar a trajetória escolar de seus filhos, dentro do seu campo de possíveis, seja pelo esforço em mantê-los na instituição de ensino, pelas conversas sobre a importância da escola e as chances que a instituição oportuniza ou por meio de sua supervisão, quando possível presencial ou via telefone e aplicativo de mensagens. Isso que é a expressão de seu esforço para mediar os filhos em uma relação o mais bem-sucedida possível, com a escolaridade.

12. Do questionário aplicado aos escolares dos 5 e 6ำ anos, há 47\% dos discentes com histórico de aprovação sem convocação para as recuperações de estudos e que contam com o acompanhamento de suas atividades escolares pela figura materna. 


\section{Projeto e desejo de ser viabilizados pela família e escolaridade}

Karine vem estabelecendo uma relação bem-sucedida com a escola, de investimento, boas notas, bem relacionada com colegas, professores, valorizada pelo aprendizado e esforço para continuar traçando esse caminho de sucesso escolar. Trata-se da trajetória escolar de uma menina que, contra as estatísticas, confirma a superação dos casos improváveis. Isso se confirma pela análise dos questionários, confirmando três possíveis grupos ou categorias de análise: a) estudantes que receberam aprovação sem nenhuma necessidade de recuperação ao longo de seu percurso escolar, até o momento da pesquisa (35\% - 47 estudantes, entre eles Karine); b) estudantes que foram aprovados, mas que em algum momento de sua trajetória escolar foram convocados às Recuperações de Estudos (51\% - 67 estudantes); e c) estudantes que já reprovaram em algum momento da sua vida escolar ( $14 \%$ - 18 estudantes - Tiago).

O perfil e as respostas de Karine é apenas $44 \%$ condizente com o perfil do seu grupo. Trata-se de um caso particular de escolaridade, em que algumas variáveis como a formação e a posição social da família não indicam probabilidade para o sucesso. O seu desempenho escolar e pertencer a uma família de mulheres bem-sucedidas, há pelo menos duas gerações, o que de certa maneira se confirma - ainda que não em absoluto - pelo esforço da avó e da mãe ${ }^{13}$, é um desses aspectos. A investigação de Ireland (2007) mostra algo sobre as questões de gênero e a escolaridade nas escolas públicas brasileiras.

A porcentagem das meninas segue em certa vantagem, com média de 10,4 anos na $4^{\text {a }}$ série. Mais aproximado da esperada do que a dos meninos que é de 10,7 anos. Entre as meninas analisadas pela pesquisa, apenas $10 \%$ se encontram "defasadas" mais de dois anos na seriação, enquanto nos meninos, a porcentagem aumenta para $16 \%$. E na idade/série própria, o número de meninas é $2 / 3$ do total contra $54 \%$ do número de garotos. (IRELAND, 2007, p. 109).

Além disso, o que a demarca nesse seleto grupo, é o fato de residir em casa própria, fruto da herança e esforço de duas gerações. Ela desconhece a escolaridade dos pais, que é inferior a dos pais dos demais colegas. A mãe declara vínculo empregatício, porém, esse vínculo se dá com empresas terceirizadas e em situação de precariedade profissional, dificultando sua presença em casa. Mas é sobretudo nas lógicas e explicações sobre a escolaridade, em resposta ao questionário, que ela se vê bem situada em sua categoria, acreditando que o principal responsável pela reprovação é o próprio aluno e que, de uma forma geral, os alunos vão para escola como muita vontade e para aprender ou para encontrar os amigos. Esses argumentos demonstram uma forte relação com a escolaridade, de uma aluna que se supera para manter uma trajetória bem-sucedida. Sua estrutura familiar e a distância da sua residência até a escola contrastam com a da maioria deste grupo, oriundos de famílias nucleares e que moram com os pais na mesma casa, na região central de Florianópolis. O deslocamento até a instituição escolar demanda um investimento de tempo e desgaste maior, se comparado aos colegas. Talvez o aspecto mais curioso seja a falta de um acompanhamento por parte de familiares nas tarefas escolares, enquanto a maioria dos estudantes é acompanhada pela mãe ou responsável feminina no contraturno. Karine permanece sozinha na maior parte do tempo e realiza as atividades escolares sem supervisão, o que exige uma maior responsabilidade e autonomia. Nesse cenário, ressaltamos as questões formuladas por Charlot (1996, p. 49) e que nos inspiram a refletir: “[...] que sentido tem para a criança o fato de ir à escola e de aprender as coisas? O que a mobiliza no campo escolar e o que a incita a estudar?”.

Frente às demandas cotidianas e responsabilidades imputadas a adolescentes nessa faixa etária, as (auto)biografias dos irmãos trazem fortes indícios de que eles apresentam consciência de sua situação de classe e da necessidade e escassez que vivenciam, por meio dos limites da condição familiar. Eles testificam preocupações que, normalmente, ficam a cargo dos adultos responsáveis, como por exemplo: aprender a lidar com pouco dinheiro; a importância do trabalho; o esforço cotidiano frente a tantas limitações; a cooperação

13. Sua mãe tem Ensino Médio incompleto, que Karine diz não saber, assim como boa parte de seus colegas não souberam responder. É interessante registrar que para aqueles que sabem, a ampla maioria das mães possuem escolaridade superior a de Marina. 
mútua; o consumo consciente; além de outras situações. As complexidades advindas das questões financeiras da família, de acordo com os relatos, foram sentidas por eles desde muito cedo, ainda quando crianças, potencializadas após a separação dos pais. Essa diligência chega a preocupá-los e, de alguma maneira, faz com que se esforcem e ajudem para minimizar tais dificuldades.

Destacamos algumas circunstâncias vividas e estratégias utilizadas pela família, posto que as mulheres responsáveis passam muitas horas por dia em seus respectivos empregos, o que impõe limites e regras aos estudantes, tentando minimizar a distância entre eles e maximizar o cuidado e a segurança dos menores. Entendendo esses limites como uma de suas integridades, eles mantém-se zelosos com tais regras que visam somente ao seu bem. Em relação a restrição na circulação em alguns espaços sem acompanhamento, as regras são mais rígidas para Karine, indicando que ocorre uma diferença no tratamento por gênero.

A divisão atual das responsabilidades entre os irmãos se resume da seguinte maneira: as mulheres são responsáveis pela limpeza e organização diárias da casa e Tiago auxilia a sua avó apenas nas atividades externas, como a limpeza do pátio e plantio da horta - atividades mais espaçadas. Isso parece uma reprodução da época de infância de Marina, na qual o irmão menor era poupado dos afazeres domésticos e tinha um maior cuidado e atenção, enquanto as meninas dividiam a pesada carga de tarefas domésticas.

Duas principais vias pelas quais os processos de socialização familiar, em camadas populares urbanas, poderiam atuar na produção de desigualdade de gênero da educação básica. Em primeiro lugar, a cobrança de que as meninas participassem da rotina de afazeres domésticos e, mais, fossem proativas para limpar e arrumar a casa, cuidar dos irmãos mais novos e assumir compromissos perante a organização domiciliar, podia servir como um incentivo ao desenvolvimento de posturas tais como organização, disciplina, iniciativa e responsabilidade. (SENKEVICS, 2015, p. 15).

Em seu relato, Karine indica ter certa responsabilidade, zelo e cuidado pelo irmão, corroborando a ideia de que as mulheres cuidam dos homens no plano doméstico. Isso que não fica tão evidente, apesar da fala de Tiago, de uma disposição: "Ela pode contar comigo". O cuidado dos irmãos mais novos pelas meninas, em parte da literatura, traz como justificativa, a faixa etária. Como se esse fato de maior idade, por si só, já daria conta desse engajamento. Senkevics $(2015$, p. 5) salienta que "é essencial revelar o caráter de gênero por trás de tal asserção, posto que uma tarefa típica de uma irmã mais velha pode não encontrar simetria em um irmão mais velho". Toda a organização, disciplina, iniciativa e responsabilidade apreendida por Karine, pode estar sendo mobilizada para a relação com a escolaridade, trazendo resultados surpreendentes.

É com uma voz tranquila e reflexiva que Karine explica como transforma as maiores demandas que recaem sobre ela, em desenvoltura e autonomia, como acaba de certo modo utilizando essa divisão desigual que a prepara para enfrentar o que antecipa, como alguém que "vai ter que se virar quando crescer". Ela relaciona a situação ao seu amadurecimento e "a saber lidar com as coisas". Para ela, seu irmão evoluiu menos, pois recebe mais proteção e atenção. Esse é um aprendizado cotidiano que Karine elabora, fruto da relação entre eles e, nesse sentido, que "lhe faz bem". A resiliência aprendida no sociológico familiar, mediada pelas mulheres, é demonstração de que um saber-de-ser capaz, responsável, habilidosa, vai se constituindo em sua personalidade e, se considerarmos a sua idade, é extraordinário.

Karine: Não, eu não preciso tanto da atenção da minha mãe. Mais, tipo... Porque eu sei que tipo... Eu vou ter que me virar quando eu crescer. Eu vejo que tipo assim, por mais que ela não me dê tanta atenção pra mim... mais pra ele... eu vejo que eu tô aprendendo a já me... Por isso... Eu sou mais responsável que ele. Eu já tô aprendendo a me cuidar mais do que ele. É... Tipo... Não se cuidar no jeito de corpo... Mais... é tipo... cuidar da casa, nas atividades da escola... Ter mais responsabilidade em tudo.

A maior estimulação nas responsabilidades de casa e em tarefas domésticas, ao que parece, tem sido um fator positivo para Karine em sua boa relação com a escolaridade. Os valores e habilidades aprendidos com uma participação efetiva na vida doméstica convergem com o exigido pela instituição escolar: “[...] manter algum grau de asseio, estar ciente de suas obrigações, adotar uma postura madura e responsável, ser assíduo e 
privar-se de parte do tempo de lazer para corresponder a expectativas advindas do adulto etc." (SENKEVICS, 2015, p. 15).

A estudante considera a escola um lugar de aprendizagem e destaca seus aspectos de sociabilidade, um lugar de encontro com seus pares, de forma presencial e de interação nas redes sociais, uma das suas atividades preferidas. Ela se mostra perfeitamente à vontade no ambiente escolar. A escola lhe oferece os saberes que lhe interessam, as condições e ambientes para estudar e, ao mesmo tempo, um clima de sociabilidade tranquilo, alegre, com diversos recursos.

Karine: Gosto, aqui tem minhas amigas pra eu estudar. E aí... Também tem internet pra toda vez que eu precisar... ou coisas que eu tenho dúvida... pra pesquisar. Ou que precisa pesquisar eu uso a internet porque em casa eu não tenho. [...] Eu gosto de [risos] é... eu gosto bastante de mexer no celular, de ficar na internet e de brincar com... De fazer bagunça com as minhas amigas. E de... Na hora que não está tendo aulas [risos] ficar bagunçando no meio da sala [risos].

Entrevistadora: Tudo o que você mencionou até o momento, está relacionado com seus amigos e atividades que você faz nos tempos livres. Mas, entre as coisas da escola o que você mais gosta?

Karine: É... Da biblioteca. É... eu gosto de ir lá para estudar e... Eu gosto... Na brinquedoteca eu não vou mais. Eu ia muito no ano passado. Esse ano eu não tô indo tanto. E... Eu gosto quando eu estou inspirada para fazer as coisas. Eu vou na biblioteca com as minhas amigas, geralmente e levo meu celular para escutar música e ficar estudando. E conversar com elas também. Aí eu vou com elas. Eu pego meu material e se a gente não se senta lá em cima nas mesas da salinha a gente senta lá embaixo nas mesinhas e fica estudando.

Suas respostas à escola se expressam por meio do envolvimento, integração, interesse, iniciativa e assertividade. O sucesso escolar distingue disciplinas, evidenciando relações que são construídas ao longo de sua trajetória, correlacionadas aos livros, projetos, metodologias, desempenho e empatia dos seus respectivos professores. O conjunto das relações com disciplinas e atividades é bem-sucedida, realizadora. Ela mostra satisfação em explicar sua organização da rotina estudantil, por meio da agenda de seu celular, garantindo que todas as atividades escolares sejam realizadas dentro do prazo. O seu engajamento e responsabilidade com a escolaridade se mostra vetor desse sucesso. Quando ela descreve a execução das tarefas, percebemos que a sua organização e compromisso alcançam igualmente o saber-fazer das atividades diárias. Suas descrições asseveram e alternam a realização das tarefas de casa em dois momentos: em espaço doméstico e na escola nos horários livres, do contraturno, entre uma disciplina e outra.

Karine: Quando eu tenho tempo eu programo os meus dias principalmente no calendário do celular... E... Eu coloco ele pra me avisar. Um dia antes, tantas horas antes. Aí ele me avisa que eu tenho que fazer. Aí eu faço a maioria, todos... Eu sempre faço normalmente sozinha ou às vezes com as minhas amigas, principalmente nos dias de aula de educação física, que a gente vai pra biblioteca. A minha mãe e a minha vó perguntam se tem deveres pra fazer e diz que é pra fazer, às vezes eu faço, mas eu deixo mais pra fazer na escola mesmo. [...] às vezes eu faço em casa. Mas, eu faço mais aqui nesse horário de intervalo. Ou lá no corredor ou na biblioteca.

Segundo Charlot (2000, p. 55), precisamos compreender em termos de "mobilização" essas crianças que vão para escola para aprender e se engajam nos estudos e nas atividades escolares. Elas estudam e se envolvem com a escolaridade, porque estudar e ir à escola são por si mesmo atividades que lhes dão prazer ou que as realizam. O autor explica a importância de demarcar bem esse tipo de relação diferente dos alunos que se encontram motivados, por algo que não o estudo ou as atividades escolares por elas mesmas, ainda que motivar possa ser um aspecto para a entrada e permanência em um processo mobilizador de aprendizado por parte do sujeito. Mobilizar-se é pôr recursos em movimento, mobilizar suas forças para fazer uso de si próprio como recurso no engajamento e engajar-se na atividade por boas razões para fazê-lo.

A situação mostra como esta mobilização vem se construindo como resultado de processos de sociologização no tecido familiar. Está em curso um processo de construção de um "projeto e desejo de 
ser", viabilizado pela escola, em continuidade ao que ocorre no núcleo familiar, transformando as dificuldades, faltas, escassez em recursos e mobiles para o melhor aproveitamento da escola e tudo que ela pode proporcionar. É claro, também, que isso ocorre pelo engajamento e protagonismo da menina, que mostra de forma objetiva e subjetiva, o quanto o desejo é constituinte e constituído pelas experiências vividas em casa e na escola, isso que Sartre (1997, p. 138) nos ajuda a explicar como uma realidade humana intimamente ligada à falta e a escassez na formação do desejo como fato humano.

Entrevistas e observações de aulas nos permitiram refletir sobre alguns aspectos dessa relação com a escolaridade, buscando o concreto e aquilo que ocorre, de fato, na vida e relações familiares e que é vivido e construído pela filha mais nova. Ao descrever e conjeturar suas condições no presente, suas narrativas estavam fortemente cunhadas com o seu passado de dificuldades, principalmente, depois da separação dos pais e pelo anseio de um futuro melhor. E, ao mesmo tempo, há algo lá na frente, muito forte, que a puxa, que é viável e possível por meio de sua escolarização. Mais uma vez nos remetemos a Sartre para evidenciar a importante relação com a temporalidade que, no caso de Karine, se assume como propulsor, um futuro que a puxa, evidenciando seu inacabamento e, ao mesmo tempo, um projeto em curso. A mediação da mãe é fundamental, mesmo que o exemplo não seja o mais significativo, mas pelo conjunto e, principalmente, pelo seu esforço em proporcionar a melhor escolaridade para os filhos. A busca, a mudança, a transformação em sua biografia se mostra como forte referência em uma relação íntima com a escolaridade. Karine compreende e legitima essa analogia. É nessa perspectiva e na relação positiva e de êxito com a escola, que a estudante também ganha o respeito, a admiração de seus familiares, principalmente, o de sua mãe.

Entrevistadora: Como você percebe na prática que o colégio está sendo importante para você conseguir alcançar seu objetivo [fazer-se veterinária].

Karine: Ele ajuda muito! [...] Ele tem me ajudado a entender e a compreender muitas coisas que para o meu futuro vai ser muito bom! Eu aprendo muitas coisas pra minha vida... Que vão me ajudar muito pra conseguir o que eu quero, que é ser veterinária. Se eu não estudar, não tem como. Eu tenho que estudar e assim... ir estudando agora até sair daqui e ir pra faculdade. E o colégio é muito bom, e eu vou sair daqui com bastante conhecimento sobre as coisas.

Entrevistadora: Karine, ao se tornar uma veterinária, como você acha que poderia melhorarem sua realidade e a da sua família?

Karine: Eu acho que melhoraria sim. Eu ia ajudar mais nas coisas da casa. Que nem pagar as contas, comprar as coisas que a gente quer e que tem vontade e hoje não dá. Eu nem peço por isso. Eu ia ajudar a minha mãe e a minha vó a ter uma consciência melhor sobre os animais, mostrar para elas que o animal não é horrível... É... que elas também se preocupassem mais com eles. [...] viajar com a minha família. Essas coisas.

O estudo (auto)biográfico realizado para compreender essas situações, escancaram a potência do futuro nas ações humanas, propulsor do movimento das crianças e adultos em circunstâncias desfavoráveis. Esse futuro em que sou presente como outro que serei, se expressa em cada ação e pensamento. Quando inviabilizado, o futuro provoca o sujeito, o desestabiliza e pode até levar a derrota definitiva. A possibilidade de ter um futuro mais confortável e mais completo, seja como uma veterinária ou qualquer outra profissão que consiga galgar por via escolar, ou ainda, como mulher em seus diferentes perfis, apontam que o ser humano é o seu presente, é o seu passado se impondo ao presente, atualizando-se ou desfragmentando-se, mas sobretudo, é constantemente tracionado por um futuro possível, desejado, que dá sentido e serve de móbile para as suas ações no presente. São as possibilidades desse mundo concreto, real, com todas suas doçuras e amarguras, que são postas na concretização porvir. 


\section{Considerações finais}

Esse estudo (auto)biográfico problematiza aspectos da relação de uma menina de 12 anos com a escolaridade, mediada por um núcleo familiar monoparental, com ênfase na relação materna. As suas ações implicam uma negação das situações que não se dissolvem e tornam-se emaranhadas no presente, vinculadas a um passado que já não se pode mudar e que, assim, se projeta em um futuro, por alcançar a realização de um possível, que ainda não foi conquistado e que lhes parece como falta.

A filha avança nos estudos por meio de uma escolaridade bem-sucedida. Faz bom uso dos recursos disponíveis e da mediação dos adultos e pares para viabilizar seus processos de realização como estudante ou filha. Ela vai construindo uma trajetória bem-sucedida em diversos aspectos, saindo da linha de probabilidade, ganhando confiança e se sentindo capaz de avançar nas diferentes disciplinas, ser aprovada não apenas nas avaliações escolares, mas também, como aluna bem-comportada. Embora suas responsabilidades no serviço doméstico não lhe sejam atraentes, a adolescente já sinaliza perceber o quanto o compartilhá-las acabou por influir positivamente no desenvolvimento de habilidades em outras esferas de sua vida.

De uma maneira geral, os dados apresentados trazem indicações da relevância do acompanhamento durante as atividades escolares por algum adulto responsável, ainda que em nosso estudo, isso ocorra de forma precária. A hipótese é a de que o investimento, se possível, tornasse a vida escolar ainda mais tranquila e realizadora. Evidenciamos, ainda, pela revisão de literatura e por questões culturais, que a responsável feminina vem se mostrando como importante referência e mediação no processo de construção de uma boa relação dos filhos com a escola, seja ela presente na escola ou em um trabalho menos visível para as instituições escolares, mas que ocorre à sua maneira. E sobre esse aspecto, houve confluência nos cômputos das pesquisas sobre o retrato da mulher brasileira, a desenhada por Cavenaghi e Alves (2018), intitulada Mulheres chefes de família no Brasil: avanços e desafios, com os resultados do IBGE (2018), Estatísticas de gênero: indicadores sociais das mulheres no Brasil, nos quais a mulher brasileira é caracterizada como principal responsável pela dedicação aos afazeres e cuidados domésticos, mostrando sua crescente escolarização e a desigualdade salarial entre homens e mulheres.

Mãe e filha trazem em suas narrativas um emaranhado de situações que demonstram a força, a resistência, a luta dessa família e, sobretudo, a crença em dias mais brandos. É aparente em suas narrações, que as (auto)biografadas queiram romper com as conjunturas atuais que lidam diariamente e que suas ações e desdobramentos despontam um ideal de algo que possam se tornar e realizar mais à frente. Elas veem essa transformação possível de ser almejada por meio dos caminhos escolares e dos saberes científicos. Por fim, as indicações desta pesquisa enriquecem e reforçam a importância dos debates ao redor do tema e destacam a importância da mulher no trabalho familiar, inclusive, com a escolaridade.

Neste estudo damos voz as suas angústias, pensamentos, emoções, desejos, valorizando as elaborações de como se apropriam das principais relações estabelecidas no núcleo familiar e que são mediações para sua escolaridade. Damos ênfase a descrição do cotidiano, de como as situações acontecem no presente e vamos investigando até surgir das suas experiências escolares, os diversos aspectos que nos permitem compreender a formação do sentido da escolaridade, do estudar. A escola é no fazer e saber, elaboração expressa pela voz de ambas, um lugar de transcendência e mobilidade social, que tem a potência de viabilizar um projeto de mulher e profissional que se encontra em curso e que só tem razão de ser como futuro que inunda o presente, tornando cada ação e atividade realizadora de seu ser, ainda que, ao longo do caminho, as adversidades se imponham como desprazer, dificuldade, angústia, medo e insegurança. Esse é o enfrentamento de toda uma vida comum, mas que se impõe de maneira bela, pela realização de um projeto de escolaridade com sentido em si mesmo. 


\section{Referências}

BERTOLINO, Pedro. Modelos Científicos. NUCA: Núcleo Castor, Florianópolis, 2008. Disponível em: https://nuca. org.br/modelos-cientificos/. Acesso em: abr. 2020.

CAVENAGHI, Suzana; ALVES, José Eustáquio Diniz. Mulheres chefes de famílias no Brasil: avanços e desafios. Rio de Janeiro: ENS/CPES, 2018.

CHARLOT, Bernard. Da relação com o saber: elementos para uma teoria. Tradução de Bruno Magne. Porto Alegre: Artes Médicas Sul, 2000.

CHARLOT, Bernard. Relação com o saber e com a escola entre estudantes de periferia. Tradução de Neide Luzia de Rezende. Cadernos de Pesquisa, São Paulo, n. 97, p. 47-63, maio 1996.

CHARLOT, Bernard; BAUTIER, Elisabeth; ROCHEX, Jean-Yves. École et savoir dans les banlieues et ailleurs. Paris: Armand Colin, 1992.

INSTITUTO BRASILEIRO DE GEOGRAFIA E ESTATÍSTICA (IBGE). Estatística de Gênero: indicadores sociais das mulheres no Brasil. Estudos e Pesquisas: informação demográfica e socioeconômica, Rio de Janeiro, n. 38, 2018. Disponível em: https://biblioteca.ibge.gov.br/visualizacao/livros/liv101551_informativo.pdf. Acesso em: 10 dez. 2018.

IRELAND, Vera Esther (coord.). Repensando a escola: um estudo sobre os desafios de aprender, ler e escrever. Brasília: UNESCO: MEC/INEP, 2007.

LAHIRE, Bernard. Sucesso escolar nos meios populares: as razões do improvável. São Paulo: Ática, 1997.

MINAYO, Maria Cecilia de Souza; SANCHES, Odécio. Quantitativo-Qualitativo: oposição ou complementaridade? Cadernos de Saúde Pública, Rio de Janeiro, v. 9, n. 3, p. 239-262, jul./set. 1993.

PATTO, Maria Helena Souza (org.). Introdução à psicologia escolar. São Paulo: Casa do Psicólogo, 1997.

PIOTTO, Débora Cristina. Trajetórias escolares prolongadas nas camadas populares. Cadernos de Pesquisa, São Paulo, v. 38, n. 135, p. 701-707, dez. 2008.

SARTRE, Jean-Paul. Crítica da razão dialética. Rio de Janeiro: DP\&A, 2002.

SARTRE, Jean-Paul. A transcendência do Ego: esboço de uma descrição fenomenológica. Cadernos Espinosanos, São Paulo, n. 22, p. 183-228, abr. 2010.

SARTRE, Jean-Paul. O ser e o nada: ensaio de ontologia fenomenológica. 3. ed. Petrópolis: Vozes, 1997.

SCHNEIDER, Daniela Ribeiro. O método biográfico em Sartre: contribuições do existencialismo para a psicologia. Estudos e Pesquisas em Psicologia, Rio de Janeiro, n. 2, p. 289-308, 2008.

SENKEVICS, Adriano Souza. Lavar a louça ou brincar na rua? Gênero, família e escola em camadas populares de São Paulo. In: REUNIÃO NACIONAL DA ANPED, 37., 2015, Florianópolis. Anais [...]. Florianópolis: UFSC, 2015.

SILVA, Jailson de Souza e. “Por que uns e não outros?”: caminhada de estudantes da Maré para a universidade. 1999. Tese (Doutorado em Educação) - Pontifícia Universidade Católica do Rio de Janeiro, Rio de Janeiro, 1999.

VIANNA, Maria Jose Braga. Longevidade escolar em famílias de camadas populares: algumas condições de possibilidade. In: NOGUEIRA, Marialice; ROMANELLI, Geraldo; ZAGO, Nadir (org.). Família e escola: trajetórias de escolarização em camadas médias e populares. Petrópolis: Vozes, 2010.

ZAGO, Nadir; CARVALHO, Marília Pinto de; VILELA, Rita Amélia Teixeira (org.). Itinerários de pesquisa: perspectivas qualitativas em sociologia da educação. Rio de Janeiro: DP\&A, 2002.

Data de submissão: 19/06/2020

Data de aceite: 06/07/2020 